\title{
Correction of Overlapping Fifth Toe Deformity with Combination of Z-Plasty and Transposition Skin Flap
}

Tekin Simsek*, Engin Yosma, Asef Abdullayev, Bulent Demir and Ibrahim Alper Aksakal

Department of Plastic, Reconstructive and Aesthetic Surgery, Ondokuz Mayis University, Samsun, Turkey

\begin{abstract}
Overlapping fifth toe is a congenital deformity and is characterized by an external rotation of the toe so that it overrides the adjacent fourth toe. Treatment of this condition aims to permanently reposition the fifth toe and includes conservative and surgical techniques. Here we present a case of severe overlapping fifth toe deformity treated with a combination of Z-plasty and a unilobed transposition skin flap technique over a limited surgical area, associated with low morbidity.
\end{abstract}

Keywords: Overlapping finger; Fifth toe; Deformity; Z plasty; Skin flap

\section{Introduction}

Overlapping fifth toe is a congenital deformity and is characterized by an external rotation of the toe so that it overrides the adjacent fourth toe [1]. A number of factors may play a part in the pathophysiology of this condition including proximal phalanx axial rotation, medial deviation of the toe, skin contracture, and a hyperextension deformity of the Metatarsophalangeal (MTP) joint as a result of extensor tendon contracture [2]. In addition to concerns regarding the appearance of the deformity, patients may experience pain during walking caused by compression of the fifth toe between the fourth toe and the shoe.

Treatment of this condition aims to permanently reposition the fifth toe and includes conservative and surgical techniques $[3,4]$. When conservative methods fail, surgical techniques may be appropriate, ranging from a simple soft tissue release to amputation [3]. Here we present a case of severe overlapping fifth toe deformity treated with a combination of Z-plasty and a unilobed transposition skin flap technique over a limited surgical area, associated with low morbidity.

\section{Case Report}

An 8-year-old male presented to our clinic with pain caused by overlapping of the fourth by the fifth toe bilaterally. Examination revealed rotation deformity, medial deviation, hyperextension of the MTP joint and skin contracture in both fifth toes (Figure 1). He had history of unsuccessful conservative treatment using toe splints.

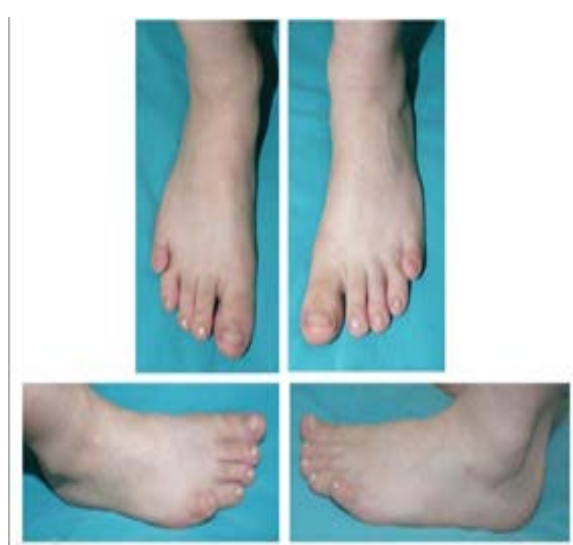

Figure 1: 'Overlapping finger' deformity is seen in fifth toes characterized with external rotation (supination), medially deviation (varus), hyperextension of MPJs and dorsal skin contractures (MPJ, metatarsophalangeal joint).
We used the Z-plasty technique to release the skin contracture band under general anesthetic. The incision extended to the junction between the web-space and sole. A lateral pedicled $1.5 \times 1 \mathrm{~cm}$ sole skin flap allowed to be transposed to the web space (Figure 2). Following flap dissection, extensor tenotomy was performed and the MTP joint capsule was released from adhesive ligamentous structures (Figure 3). Splint dressings were used during the 3 -week follow-up period. The surgical outcome was good, with minimal residual overlapping on the left foot in the early postoperative period (Figure 4). Patient was followed up at 24 months. Finally, no recurrence or residual deformity was observed (Figure 5).

\section{Conclusion}

A number of conservative approaches have been described for the treatment of an overlapping fifth toe including splints, roller bandages and the wearing of broad shoes [3,4]. A previous study found that conservative treatment does result in improvement or cure in

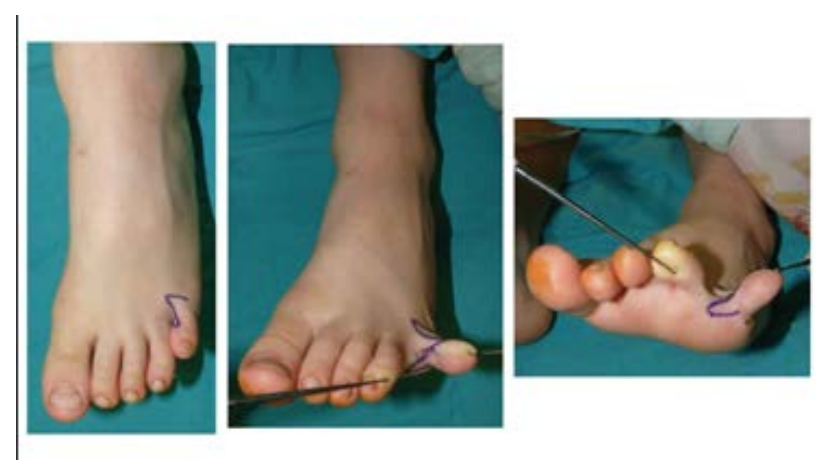

Figure 2: Designed Z plasty through contracture band and lateral based unilobed skin flap are seen.

*Corresponding author: Simsek T, MD, Associate Professor, Department of Plastic, Reconstructive and Aesthetic Surgery, Ondokuz Mayis University, Faculty of Medicine, Samsun, Turkey, Tel: +90 532 4085024; Fax: +90 36245760 41; E-mail: drtekinsimsek@hotmail.com

Received December 18, 2014; Accepted March 14, 2015; Published March 21, 2015

Citation: Simsek T, Yosma E, Abdullayev A, Demir B, Aksakal IA (2015) Correction of Overlapping Fifth Toe Deformity with Combination of Z-Plasty and Transposition Skin Flap. Surgery Curr Res 5: 222. doi:10.4172/2161-1076.1000222

Copyright: $\odot 2015$ Simsek T, et al. This is an open-access article distributed under the terms of the Creative Commons Attribution License, which permits unrestricted use, distribution, and reproduction in any medium, provided the original author and source are credited. 


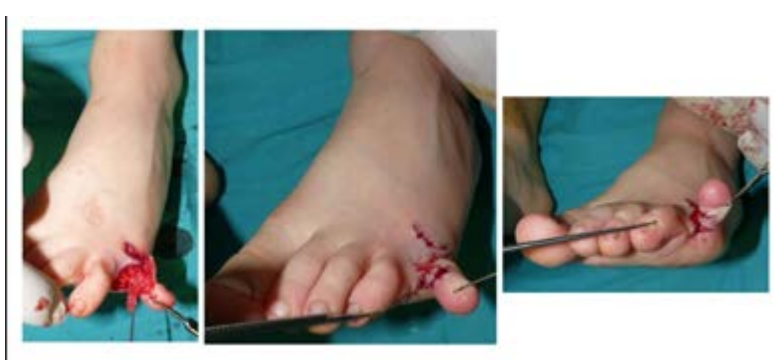

Figure 3: MPJ capsule was dissected from medial, dorsal and lateral surrounding soft tissues after the flaps elevation. EDL tenotomy was made and flaps were transposed appropriately (EDL, Extensor Digitorum Longus).
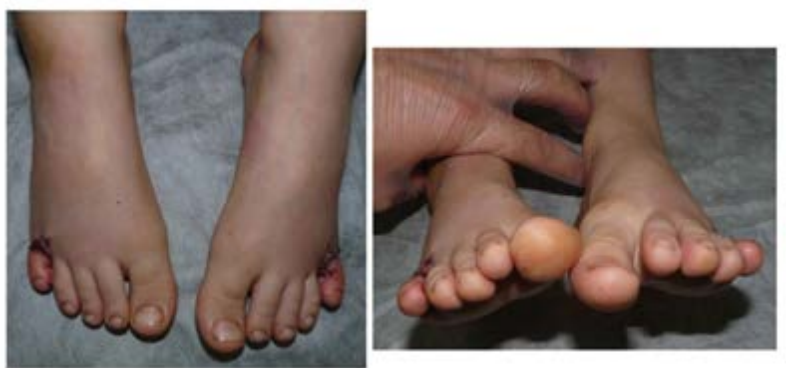

Figure 4: In early postoperative period, correction of deformity is seen (3th week)

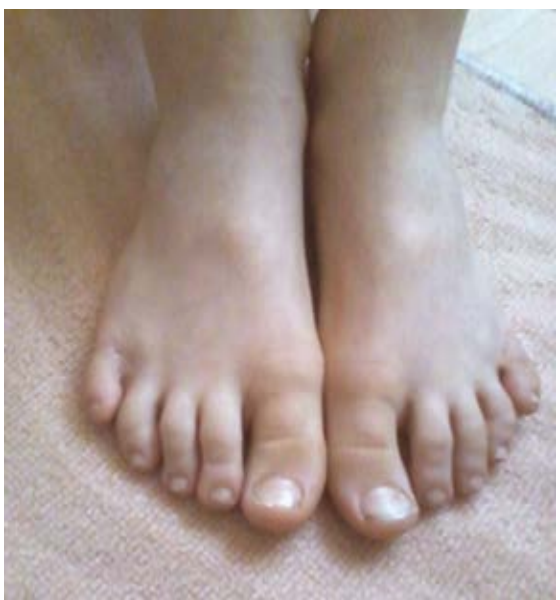

Figure 5: In late postoperative period (24th month), no any residual deformity or recurrence was observed. Final functional outcome was good.

$94 \%$ of newborns but requires a long treatment period [4]. Surgery is indicated after unsuccessful conservative treatment [5]. In mild deformities, all that may be required is the release of skin contractures. However, moderate and severe cases may require extensor tendon tenotomy, or transferring to the abductor quinti tendon, partial or total phalangectomy, syndactylization to the fourth toe or even amputation
[1-5].

Inadequate soft tissue release may cause under-correction or recurrence of the problem [3]. In addition, the excessive soft tissue release necessary to treat the condition may compromise vascular supply [3]. In our case we performed a Z-plasty to treat the skin contracture combined with a transposition flap, using excessive sole skin, to achieve adequate skin release. Using an additional transposition flap prevents excessive soft tissue dissection of the toe and decreases the risk of vascular compromise. We also performed Extensor Digitorum Longus (EDL) tenotomy and MTP joint release to further alleviate the medial deviation.

In conclusion, it is possible to achieve adequate correction of an overlapping fifth toe without excessive soft tissue dissection through the use of combined local flaps. These can be generated from the excessive skin resulting from the overlapping deformity.

\section{References}

1. Weber RB (1982) Surgical criteria for correcting the overlapping fifth toe. $J$ Foot Surg 21: 30-36.

2. Bogy LT, Vranes R, Goforth WP, Caporusso JM (1992) Correction of overlapping second toe deformity: long-term results including a 7-year followup. J Foot Surg 31: 319-323.

3. Coughlin MJ (2002) Lesser-toe abnormalities. J Bone Joint Surg Am 84 1446-1469.

4. Smith WG, Seki J, Smith RW (2007) Prospective study of a noninvasive treatment for two common congenital toe abnormalities (curly/varus/ underlapping toes and overlapping toes). Paediatr Child Health 12: 755-759.

5. Talusan PG, Milewski MD, Reach JS Jr (2013) Fifth toe deformities: overlapping and underlapping toe. Foot Ankle Spec 6: 145-149. 